\title{
Phenolic Content and Antioxidant Activity of Cantaloupe (Cucumis melo var. cantalupensis) and Food Application
}

\author{
Marwa Ezz El-Din Ibrahim, Hany Gaber El-Masry \\ Nutrition and Food Science Department, Faculty of Home Economic, Helwan University, Cairo, Egypt \\ Email address: \\ h_g_masry@yahoo.com (H. G. El-Masry), marwy_2004@yahoo.com (M. E. El-Din Ibrahim) \\ To cite this article: \\ Marwa Ezz El-Din Ibrahim, Hany Gaber El-Masry. Phenolic Content and Antioxidant Activity of Cantaloupe (Cucumis melo var. \\ cantalupensis) and Food Application. International Journal of Nutrition and Food Sciences. Vol. 5, No. 1, 2016, pp. 16-24. \\ doi: 10.11648/j.ijnfs.20160501.13
}

\begin{abstract}
The objectives of this study were to determine phenolic content and antioxidant activity of methanolic extracts from different parts of cantaloupe (skin, seed and flesh), and to evaluate the efficiency of using cantaloupe skin wastes methanolic extracts at concentrations of 200,400 and 600 ppm, respectively by compared with BHA on oxidative stability of mayonnaise incubated at $40^{\circ} \mathrm{C}$ to accelerate the oxidation for 60 days. The flesh extract give the highest yield (62.87 $\pm 2.3 \mathrm{~g}$ extract/100 g powder) whilst the lowest yield was obtained from the seed $(2.866 \pm 0.06 \mathrm{~g}$ extract/100 g powder) (p $<0.05)$. The skin extract showed the highest total phenolic content $(8.47 \pm 0.21 \mathrm{mg}$ GAE/g extract) and total flavonoid content $(5.23 \pm 1.32 \mu \mathrm{g}$ $\mathrm{RE} / \mathrm{g}$ extract) accompanied with best antioxidant activity through antioxidant assay $(\mathrm{p}<0.05)$. For mayonnaise stability show sample treated with CSE at level $400 \mathrm{ppm}$ showed the lowest value for acid value $(0.296 \pm 0.00 \mathrm{mg} \mathrm{KOH} / \mathrm{g}$ fat $)$ and peroxide value $(6.56 \pm 0.07$ meq.O2/ $\mathrm{kg}$ fat $)$ at the end day of storage 60 day. There is no significant between it and BHA at 60 day. Thus, these results suggest that methanolic extracts of skin cantaloupe may serve as a potential source of natural antioxidant for food, nutraceutical application and could be used to retard fat auto-oxidation.
\end{abstract}

Keywords: Cantaloupe, Total Phenolic, Total Flavonoid, Antioxidant Activity, Natural Antioxidants, Oxidative Stability, Mayonnaise, BHA

\section{Introduction}

Antioxidants (natural and synthetic) play a significant role in retarding lipid oxidation reactions in food products. The detrimental effects of excessive lipid oxidation such as formation of off-flavors and undesirable oxidized chemical compounds (aldehydes, ketones and organic acids) are well known (Saad et al., 2007). Synthetic antioxidants (e. g., TBHQ, BHA and BHT) are widely used as food additives, but their application has been reassessed because of possible toxic or carcinogenic components formed during their degradation (Jo et al., 2006; Pitchaon et al., 2007). A number of natural antioxidants have been added during food processing and have elongated the shelf life and oxidative stability of stored products (Chenn et al., 2008; Ebrahimabadi et al., 2010; Jang et al., 2012; Xiaowei et al., 2011).

A huge amount of plant biomass wastes are produced yearly as by-products from the agro-food industries. These wastes are attractive sources of natural antioxidants. The high concentration of phenolic compounds present in peels, skins and seeds supports the utilization of these residues as a source of natural antioxidants. Phenolic compounds exhibit a wide range of physiological properties such as antiallergenic, antiatherogenic, anti-inflammatory, anti-microbial, antioxidant, anti-thermobiotic, cardio protective and vasodilatory effects (Balasundran et al., 2006). They work by preventing the formation of new free radical species, converting existing free radicals into less harmful molecules and preventing radical-chained reactions (Rodriguez et al., 2007). For instance, phenolic compounds such as, quercetin and ellagic acid, are good antioxidants that able to protect body cells from injuries caused by reactive oxygen and nitrogen species (Sroka \& Cisowski, 2003).

The Cucurbitaceae family includes several species of cultivated plants of great economic importance, including watermelon (Citrullus lanatus L.), squash (Cucurbita maxima L.), cucumber (Cucumis sativus L.) and cantaloupe (Cucumis melo L.) (Ritschel et al., 2004). Cantaloupe is one of the most consumed fruit crops worldwide specially in Egypt due to its pleasant flavour and nutritional value. Cantaloupes are a diverse group of fresh, dessert fruits that includes the 
orange flesh cantaloupes, green flesh honeydew, and mixed melons. A previous study showed that cantaloupe pulp extract possesses high antioxidant and anti-inflammatory properties (Vouldoukis et al., 2004). However, antioxidant assessment on different parts of C. melo is very limited (Mariod \& Matthaus, 2008). Thus, most of the objectives of the study were to determine the phenolic content and its activities from different parts of cantaloupe.

From an environmental and economical perspective, it is very important that plant by-products produced by agro-food industry be used in food industry. However, mayonnaise, the most famous consumption by youth and child in Egypt and many countries, undergoes oxidative degradation during storage, resulting in alteration of major quality parameters affecting its suitability for consumption. Development of rancidity reduces the shelf life of the product, which ultimately affects consumer acceptability (Mehta, 2006; Mariod et al., 2010). The use of synthetic antioxidants is less desirable due to current recommendations and consumer preferences, so there is growing interest in finding alternative solutions, and thus results in preventing lipid oxidation of mayonnaise by using natural antioxidant. Therefore, the objectives of this study were; (1) to determine the phenolic content and antioxidant activities of methanolic extracts from different parts of cantaloupe, (2) to evaluate the efficiency of using agro cantaloupe wastes methanolic extracts in improving the nutritional value and oxidative stability of mayonnaise during storage under thermal oxidative conditions.

\section{Materials and Methods}

\subsection{Materials and Chemicals}

Cantaloupe (Cucumis melo var) plant, egg, refined sun flower oil and Arabic gum were purchased from the local market from Egypt. The chemicals used in this study were of analytical reagent grade that include: methanol, chloroform, ethyl alcohol gallic acid 1, 1-diphenyl-2-picrylhydrazyl (DPPH); Folin-Ciocalteu's phenol reagent aluminium trichloride $\left(\mathrm{AlCl}_{3}\right)$, sodium carbonate $\left(\mathrm{Na}_{2} \mathrm{CO}_{3}\right)$, phenolphthalein, potassium hydroxide $(\mathrm{KOH})$, potassium iodide, sodium thiosulphate $\left(\mathrm{Na}_{2} \mathrm{~S}_{2} \mathrm{O}_{3} .5 \mathrm{H}_{2} \mathrm{O}\right)$ El-gomheria company (St. sherif, Cairo, EGY); starch, butyl hydroxyl anisole (BHA), rutin, and, potassium sorbate, sodium hypo phosphite $\mathrm{NaH}_{2} \mathrm{PO}_{2}$ Sigma (St. El-Reyada, Nasr city, EGY).

\subsection{Sample Preparation}

Cantaloupe (C. melo) plants were cleaned and separated into three different parts namely, skin, flesh and seed. All parts were individually dried using solar energy (Bala et al., 2009).

\subsection{Methanol Extraction}

Different parts of cantaloupe were respectively pulverised into fine powder using a stainless steel blender (Bruan Commercial,, GER) and mixed with (80\%) aqueous methanol at the ratio of $1: 10(\mathrm{w} / \mathrm{v}, 1 \mathrm{~g}$ powder: $10 \mathrm{ml}$ methanol). Then these mixtures were manually swirled for 15 min, then wrapped with aluminum foil to prevent light degradation during extraction (Yu et al., 2005), and left over night at room temperature $\left(25^{\circ} \mathrm{C}\right)$. After that, these mixtures were individually filtered through Whatman filter paper No. 1. The filtrates were individually pooled and methanol was removed from the filtrates under reduced pressure (Rotavapor R210, Buchi, Postfach, Flawil, Switzerland). Finally, cantaloupe extracts were cooled in a desiccator for $30 \mathrm{~min}$ before the yield of each extract was calculated. The methanolic extracts from different parts of cantaloupe were kept at $-10^{\circ} \mathrm{C}$ prior to further analyses.

\subsection{Total Phenolic Content (TPC)}

Total phenolic contents of cantaloupe extracts were determined using Folin-Ciocalteu assay (Meda, et al., 2005), partially modified in our laboratory. Briefly, $0.1 \mathrm{ml}$ of diluted extract $(10 \mathrm{mg}$ in $10 \mathrm{~mL}$ methanol) these solutions were mixed with $2.5 \mathrm{ml}$ of 10 -fold diluted Folin-Ciocalteau reagent, and $2.0 \mathrm{ml}$ of $7.5 \%$ sodium carbonate $\left(\mathrm{Na}_{2} \mathrm{CO}_{3}\right)$. After incubation at $40^{\circ} \mathrm{C}$ for $30 \mathrm{~min}$, the absorbance of the reaction mixtures were measured at $760 \mathrm{~nm}$ by using a spectrophotometer (Jenway-UV-VIS Spectrophotometer). Gallic acid was used as a standard for preparing the calibration curve, and TPC of cantaloupe extracts were expressed in milligram gallic acid equivalents ( $\mathrm{mg} \mathrm{GAE} / \mathrm{g}$ extract).

\subsection{Total Flavonoid Content (TFC)}

Total flavonoid content was determined by the aluminium calorimetric method Quettier-Deleu et al., (2000), using rutin as a standard. Briefly, $(150 \mu 1)$ of the diluted sample solution (10 $\mathrm{mg}$ in $10 \mathrm{~mL}$ methanol) was mixed with $150 \mu \mathrm{l}$ of $2 \% \mathrm{AlCl}_{3}$. After $10 \mathrm{~min}$ of incubation at ambient temperature, the absorbance of the supernatant was measured at $435 \mathrm{~nm}$ by using a spectrophotometer (Jenway-UV-VIS Spectrophotometer). Three replicates were made for each test sample. The total flavonoid content was expressed as rutin equivalents in microgram per gram extract ( $\mu \mathrm{g} R \mathrm{RE} / \mathrm{g}$ extract).

\subsection{DPPH Radical-Scavenging Activity}

The effect of extracts on 1, 1-diphenyl-2-picrylhydrazyl (DPPH) free radical was estimated according to the procedure described by $\mathrm{Yi}$ et al., (2008), with some modifications. An aliquot of $1.5 \mathrm{ml}$ of sample solution (1 $\mathrm{mg} / \mathrm{ml}$ ) was mixed with $1.5 \mathrm{ml}$ of methanolic solution of $\mathrm{DPPH}^{-}(0.2 \mathrm{mM})$. The reaction mixture was incubated for 30 min in the dark at room temperature. The absorbance of the resulting solution was measured at $517 \mathrm{~nm}$ with a spectrophotometer. For the control, the assay was conducted in the same manner but methanol was used instead of sample solution. DPPH. scavenging capacity of the tested samples was measured as a decrease in the absorbance and was calculated by using the following equation: 


$$
\text { Scavenging activity }(\%)=\frac{\mathrm{Ac} \__{-} \mathrm{As}}{\mathrm{Ac}} \times 100
$$

where Ac and As are the absorbances at $517 \mathrm{~nm}$ of the control and sample, respectively.

\subsection{Food Applications Using Cantaloupe Skin Extract}

From the our study, it was found that the cantaloupe skin extract (CSE) is more phenolic, flavonoid content and more antioxidant activity comparison with other extracts investigated. Therefore cantaloupe processing wastes methanolic extract was used to study the Stability of mayonnaise enriched with (CSE) against rancid. The mayonnaise made according to the method described by Randall (2012), Arabic gum used as stabliser and potassium sorbate was used as antifungal at level $(0.1 \%)$. Mayonnaise samples were divided in to five portions and treated as follows:-

Portion (1)

Was kept without additives and was considered to be as a negative control $(\mathrm{C})$.

Portion (2)

Was treated with 200 ppm BHA and was considered to be as positive control $(\mathrm{C} 1)$.

Portions (3, 4 and 5)

Were treated with 200, 400 and 600 ppm of CP methanolic extract respectively, (T1, T2 and T3).

All samples were incubated at $40^{\circ} \mathrm{C}$ to accelerate the oxidation for 60 days. Samples were analyzed in the zero time, half time and at the end of the storage for acid value $(\mathrm{AV})$, peroxide value $(\mathrm{PV})$.

\subsection{Acid Value}

Acid value was determined according to the $A$. O.A.C. method $(969.17,2000)$ as follows: A known weight $(2 \mathrm{~g})$ of the oil was dissolved in a neutral ethyl alcohol $(30 \mathrm{ml})$. The mixture was boiled on a water bath for $2 \mathrm{~min}$ and then titrated with potassium hydroxide solution $(0.1 \mathrm{~N})$ in the presence of phenolphthalein as an indicator. Acid value is expressed as mg $\mathrm{KOH}$ required to neutralize the acidity in one gram oil.

\subsection{Peroxide Value}

The mayonnaise treated with heat process to obtain oil. Peroxide value was determined according to Method ( $A$. $O$. A. C. 2000, Number 965.33) with some modification as follows: Oil sample $(2 \mathrm{~g})$ was dissolved in $20 \mathrm{~mL}$ chloroform: acetic acid (1: $2, \mathrm{v} / \mathrm{v})$ then $1 \mathrm{~g}$ potassium iodide was added and the mixture was vortexed for $1 \mathrm{~min}$ in bath water. About $20 \mathrm{ml}$ Potassium iodide solution $5 \%$ and $50 \mathrm{~mL}$ distilled water were added. The liberated iodine was titrated with sodium thiosulfate $(0.1 \mathrm{~N})$ in the presence of $0.5 \mathrm{~mL}$ starch solution as indicator. Peroxide value is expressed as miliequivalent $\mathrm{meq} / \mathrm{kg}$, it was determined by the following equation:

$$
\begin{aligned}
& \text { Peroxide value }(\text { meq } / \mathrm{kg})=\frac{(\mathrm{S}-\mathrm{B}) \times \mathrm{N} \times 1000}{\mathrm{G}} \\
& \mathrm{S}=\mathrm{mL} \mathrm{Na}_{2} \mathrm{~S}_{2} \mathrm{O}_{3} \text { sample; } \mathrm{B}=\mathrm{mL} \mathrm{Na} 2 \mathrm{~S} 2 \mathrm{O} 3 \text { blank; } \mathrm{N}= \\
& \text { normality } \mathrm{Na}_{2} \mathrm{~S}_{2} \mathrm{O}_{3} ; \mathrm{G}=\text { oil weight. }
\end{aligned}
$$

\subsection{Organoleptic Evaluation}

The trained panelists $(\mathrm{n}=10)$ from Nutrition and Food Science Department were asked to evaluate color, odor, taste, texture and general acceptability of mayonnaise on score sheet as follows: very good (9-10), good (7-8), acceptable (56), weak (3-4), very weak (1-2) according to Lanza, et al.(1995).

\subsection{Identification of Phenolic Compounds in Cantaloupe Skin}

A total of $20 \mathrm{mg}$ dried cantaloupe skin powder sample was extracted for 15 min using $750 \mu \mathrm{L} 80 \%$ methanol (v/v, pH 4, phosphoric acid) in an ultrasonic water bath (Sonorex digital $10 \mathrm{p}$, Bandelin) on ice. Sample was centrifuged for $5 \mathrm{~min}$ at $6000 \mathrm{rpm}$. The supernatants were collected and the pellets were re-extracted twice more with $500 \mu \mathrm{L} 80 \%$ methanol. The combined supernatants from sample were reduced to near dryness in a centrifugation evaporator (Speed Vac, SC 110 ) at $25^{\circ} \mathrm{C}$. Sample was then made up to $1 \mathrm{ml}$ with $40 \%$ acetonitrile. The samples were filtrated using $0.22 \mathrm{~lm}$ filter, and then analyzed with HPLC (Dionex Summit P680A HPLC-System) of Methods at laboratory of Food Biotechnology Department, Institute of Food Technology and Food Chemistry, Faculty of Process Sciences, Technical University of Berlin (Riedel et al., 2012).

\subsection{Statistical Analysis}

Statistical analysis for the obtained data was carried out using SPSS version 20 computer program (Dominick and Derrick, 2001). All data were expressed by means and standard deviations of three replicates and were compared using one-way ANOVAs and least significant difference (LSD) values with different letters within the same column differ significantly at $\mathrm{P}<0.01-0.05$.

\section{Results and Discussion}

\subsection{Extraction Yield from Cantaloupe}

The yield of extracts with different parts varied from $2.866 \pm 0.06$ to $62.87 \pm 2.3 \mathrm{~g}$ extract/100 g powder (Fig. 1). Variation in the extraction yields of different part extracts might be attributed to differences in polarity of compounds found in plants such differences have been reported by (Prakasha et al. 2001). Among all tested extracts, the highest and the lowest yields were respectively obtained from the flesh and seed of cantaloupe $(p<0.05)$. The yield of methanolic extracts from different parts of cantaloupe is presented in the following order: flesh $>$ skin $>$ seed $(\mathrm{p}<$ 0.05). The resulted obtained was agreed with Ismail et al., 
(2010) who found that, the highest extraction yield was in flesh cantaloupe extract and the lowest was in seed cantaloupe extract. On the other hand, low extraction yield of cantaloupe seed is probably due to the low solubility of major components of the seed (for instance, fat, starch and protein that are usually present in large amount in the seed) in methanol.

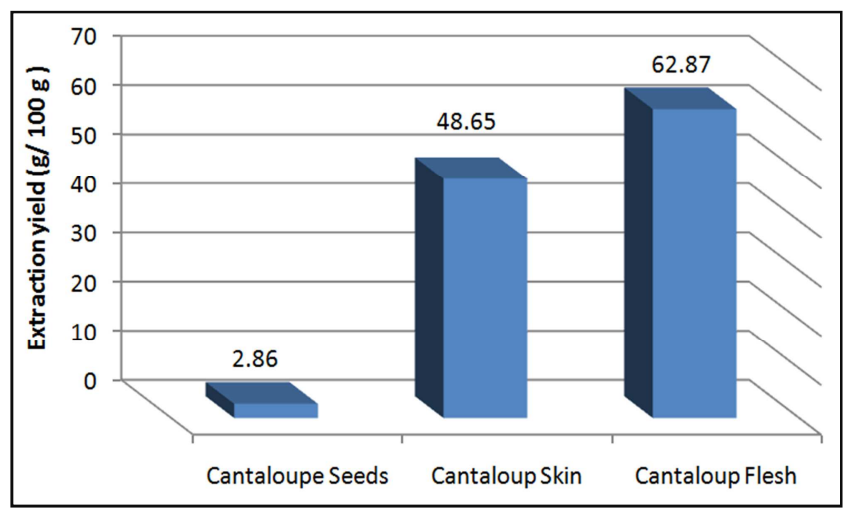

*Means Values are statistically different $(\mathrm{p}<0.05)$.

Fig. 1. Yield of extracts $(\mathrm{g} / 100 \mathrm{~g})$ for different part form cantaloupe. Values are expressed as mean $\pm S E$.

\subsection{Total Phenolic Content and Total Flavonoid Content}

Table 1 presents total phenolic content and total flavonoid content of cantaloupe methanolic extracts. The total phenolic content in the cantaloupe extracts was determined using Gallic acid as standard (the standard curve equation: $\mathrm{y}=$ $0.0161 \mathrm{x}-0.0007, \mathrm{R}^{2}=0.996$. A calibration curve was prepared (figure 2) and the total phenolic content of the extract was expressed as milligram of Gallic Acid Equivalent per gram of extract i. e. mg GAE/g extract. The amount of TPC varied in the different extracts, ranging from 1.85 to $8.47 \mathrm{mg} \mathrm{GAE} / \mathrm{g}$ extract. In general, the results stated that methanol $80 \%$ have better extracting phenolics from cantaloupe parts extracts owing to their higher polarity and good solubility (Kequan and Liangli, 2004).

The highest content of total phenolic compounds was detected in the cantaloupe skin extract $(8.47 \mathrm{mg}$ GAE/g extract) whereas the lowest content was measured in the seeds extract $(1.85 \mathrm{mg}$ GAE$/ \mathrm{g}$ extract) $(\mathrm{p}<0.05)$. Total phenolic content of cantaloupe extracts is arranged in the following descending order: skin $>$ flesh $>$ seed $(p<0.05)$. This finding is in agreement with previous study which reported that total phenolic content of skin extract was higher than other parts of the cantaloupe parts flesh and seeds (Ismail et al., 2010). Several studies have revealed that the phenolic content in the plants are associated with their antioxidant activities, probably due to their redox properties, which allow them to act as reducing agents, hydrogen donors, and singlet oxygen quenchers (Chang et al., 2001).

Table 1. Extraction yield, total phenolic content and total flavonoid content of cantaloupe extracts $(n=3)$.

\begin{tabular}{|c|c|c|}
\hline Part of Cantaloupe & Total phenolic content (mg GAE/g extract) & Total flavonoid content ( $\mu \mathrm{g}$ RE/g extract) \\
\hline Seed & $1.85^{\mathrm{c}} \pm 0.03$ & $1.61^{\mathrm{c}} \pm 0.74$ \\
\hline Skin & $8.47^{\mathrm{a}} \pm 0.21$ & $5.23^{\mathrm{a}} \pm 1.32$ \\
\hline Flesh & $4.23^{\mathrm{b} \pm} 0.08$ & $2.05^{b} \pm 0.16$ \\
\hline
\end{tabular}

Values with different superscript letters within the same column are statistically different $(\mathrm{p}<0.05)$.

Values are expressed as mean $\pm \mathrm{SE}$.

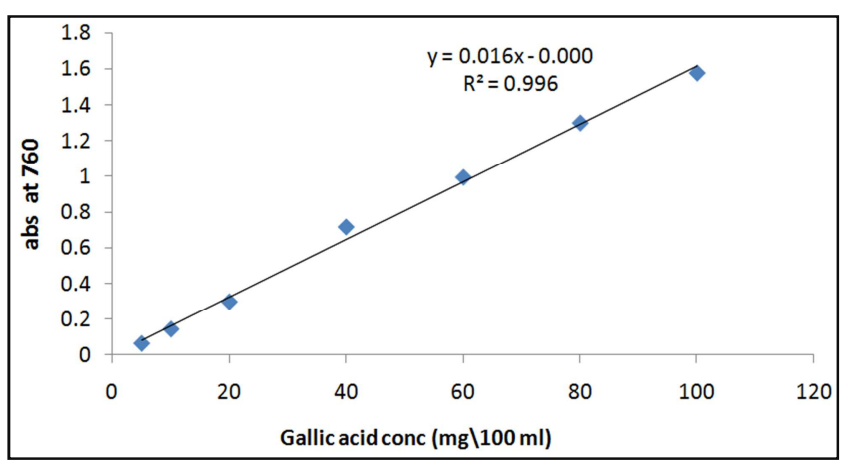

Fig. 2. Calibration curve of Gallic acid.

The concentration of flavonoids in methanolic cantaloupe extracts was determined using spectrophotometric method with aluminum chloride. The total flavonoid content (TFC) was determined from the calibration curve of rutin ( $\left.\mathrm{Y}=0.014 \mathrm{x}-0.046, \mathrm{R}^{2}=0.999\right)$ figure 3 , and expressed as microgram of rutin equivalent per gram of extract i. e. $\mu \mathrm{g} \mathrm{RE} / \mathrm{g}$ extract in table 1 . The total flavonoid content of cantaloupe extracts was varied considerably from 1.61 to $5.23 \mu \mathrm{g} \mathrm{RE} / \mathrm{g}$ extract. The data showed that the highest flavonoid content was observed in the skin extract $(5.23 \mu \mathrm{g} \mathrm{RE} / \mathrm{g}$ extract) and the lowest content was observed in the extract of the seed $(1.62 \mu \mathrm{g}$ $\mathrm{RE} / \mathrm{g}$ extract $)(\mathrm{p}<0.05)$. Total flavonoid content of cantaloupe extracts is arranged in the following order: skin $>$ flesh $>$ seed $(p<0.05)$. The total flavonoid content of cantaloupe extracts goes well with the total phenolic content. The obtained results tend to that the flavonoids are the major phenolic compounds present in cantaloupe plant. These facts agreed with [30] YanishlievaMaslarova, (2001) who found that, Flavonoids are the most common and widely distributed group of plant phenolic compounds, which usually are very effective antioxidants.

Flavonoids are well-known antioxidant constituents of plants and are known to possess a broad spectrum of biological and chemical activities including radical scavenging activity [31] (Miliauskas et al., 2010). It have been reported to be responsible for antioxidant activities of plants through their scavenging or chelating activity [32] [33] [34] (Das and Pereira, 1990; Ghimire et al., 2011; and Kessler et al., 2003). 


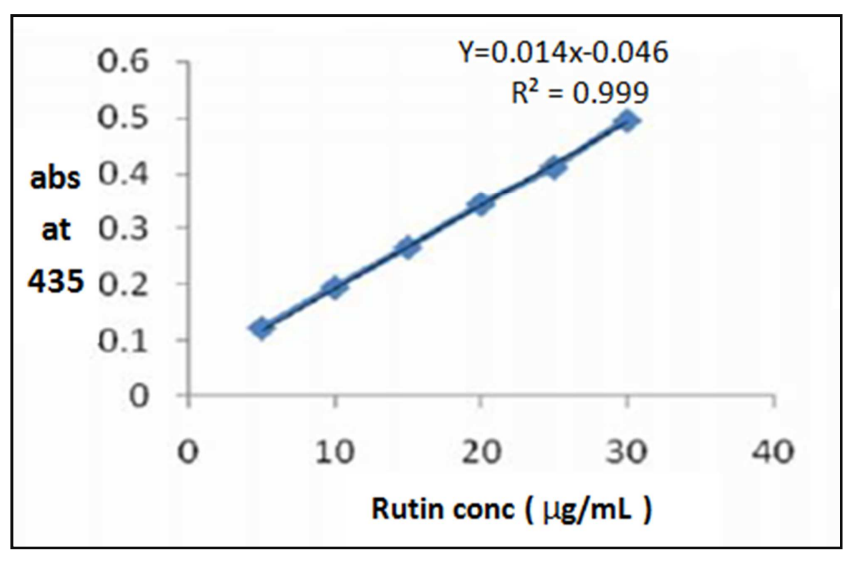

Fig. 3. Calibration curve of Rutin.

\subsection{Radical-Scavenging Activity}

The effect of antioxidants on DPPH radical scavenging is thought to be due to their hydrogen-donating ability. DPPH is a stable free radical and accepts an electron or hydrogen radical to become a stable diamagnetic molecule (Soares et al., 1997).

Table 2. DPPH radicals scavenging activity of cantaloupe methanolic extracts $(n=3)$.

\begin{tabular}{ll}
\hline Cantaloupe Extracts & DPPH radical scavenging activity (\%) \\
\hline Seed & $48.55^{\mathrm{c}} \pm 0.84$ \\
Skin & $91.73^{\mathrm{a}} \pm 0.35$ \\
Flesh & $66.36^{\mathrm{b}} \pm 0.95$ \\
\hline
\end{tabular}

Values with different superscript letters within the same column are statistically different $(\mathrm{p}<0.05)$.

Values are expressed as mean $\pm \mathrm{SE}$.

The results of DPPH radicals scavenging activity RSA of cantaloupe methanolic extracts are represented in (table 2). The results clearly indicated that all extracts exhibited antioxidant activity. The extracts that contained high amount of TPC (Table 1) showed high RSA. In general, DPPH scavenging activity values of all extracts sample tested samples ranging from $48.55 \pm$ to $91.73 \pm(\%)$. The DPPH radical scavenging activity is arranged in the following descending order: skin $>$ flesh $>$ seed $(\mathrm{p}<0.05)$. This finding is in agreement with (Ismail et al., 2010). In this study, DPPH radical scavenging activity of cantaloupe extracts shows similar trend with the result of total phenolic content and total flavonoid, indicating that DPPH radical scavenging activity of cantaloupe extracts is highly related to the amount of phenolic compounds especially flavonoids that present in the extracts. It has been proved that the antioxidant activity of plant extracts is mainly ascribable to the concentration of phenolic compounds in the plant (Heim et al., 2002).

The results of the DPPH_radical scavenging assay suggest that components involving the extracts are capable of scavenging free radicals via electron- or hydrogen-donating mechanisms and thus might be able to prevent the initiation of deleterious free radical mediated chain reactions in susceptible matrices. This further shows the capability of the extracts to scavenge different free radicals in different systems, indicating that they may be useful therapeutic agents for treating radical-related pathological damage. The effect of antioxidants on DPPH radical scavenging is thought to be due to their hydrogen-donating ability, DPPH is a stable free radical and accepts an electron or hydrogen radical to become a stable molecule (Gulcin et al., 2004).

\subsection{Identification of Phenolic Compounds}

Up to four phenolic compound detected in cantaloupe peel extract are shown in table (3). The amount of phenolic compounds is an important factor when evaluating the quality of different extracts, it involved for their resistance to oxidation and the properties attributed to this antioxidant (Moure et al., 2001). Phenolic compounds were identified in cantaloupe skin namely, 4-hydroxybenzoic acid, vanillin, chlorgenic acid, and coumaric acid. The main phenolics identified in extract 4-Hydroxybenzoic acid with amount $326.2 \mu \mathrm{g} / \mathrm{g} \mathrm{dw}$.

Moure et al. (2001) reported that the antioxidant compounds from residual sources could be used for increasing the stability of foods by preventing lipid peroxidation and also for protecting oxidative damage in living systems by scavenging oxygen radicals. It is well known that total antioxidant activity of waste extracts was line early proportional to the concentration of total phenolics.

Table 3. Identification of phenolic extracts of cantaloupe peel.

\begin{tabular}{ll}
\hline Phenolic compounds $(\boldsymbol{\mu g} / \mathbf{g} \mathbf{~ d w})$ & methanolic extract cantaloupe Skin \\
\hline 4-Hydroxybenzoic acid & 326.2 \\
Vanillin & 197.4 \\
Chlorogenic acid & 65.9 \\
Coumaric acid & 81.1 \\
\hline
\end{tabular}

\subsection{Food Applications Using Cantaloupe Skin Extract}

Oxidative stability of mayonnaise treated with cantaloupe peel extract.

- Acid values

The changes in the acid values of mayonnaise blended with different portions of cantaloupe skin extract during storage at $\left(40^{\circ} \mathrm{C}\right)$ are given in table (4). The $\mathrm{AV}$ remained without noticeable changes within the first twenty days of storage for all treatments including the control. Slight increases in AV were observed until 40 days of storage period then considerable increase in $\mathrm{AV}$ was recorded up to the end of storage period (60 days). The highest change in acid value at the end of storage period was shown for control (AV increased significant from $0.100 \pm 0.00$ at the beginning of experiment to $0.523 \pm 0.01$ at the end of storage period $60 \mathrm{~d}$ ). Data presented in table 5 show clearly that the AV of mayonnaise was affected by enrichment with cantaloupe skin extracts. In the end day of storage $60 \mathrm{~d}$, The higher oxidative stability of mayonnaise showed for samples treated with CS extracts at 400 and 600 ppm $(0.296 \pm 0.00$ and $0.266 \pm 0.01 \mathrm{mg} \mathrm{KOH} / \mathrm{g}$ fat, respectively) compared with sample treated with BHA $(0.310 \pm 0.00 \mathrm{mg}$ $\mathrm{KOH} / \mathrm{g}$ fat, respectively), the differences was not significant at $(\mathrm{p}<0.05)$ as showed In table 5. 
Table 4. Effect of methanol extracts of cantaloupe skin at different concentration on the $\mathrm{AV}$ ( $\mathrm{mg} \mathrm{KOH} / \mathrm{g}$ fat) of mayonnaise during storage ( $\mathrm{n}=3)$. *

\begin{tabular}{llllll}
\hline \multirow{2}{*}{ Storage } & Treatment & C1 & T1 & T2 & T3 \\
\cline { 2 - 6 } & $\mathbf{C}$ & $0.100^{\mathrm{d}} \pm 0.00$ & $0.101^{\mathrm{d}} \pm 0.00$ & $0.100^{\mathrm{d}} \pm 0.00$ & $0.103^{\mathrm{c}} \pm 0.01$ \\
0 day & $0.100^{\mathrm{d}} \pm 0.00$ & $0.190^{\mathrm{c}} \pm 0.05$ & $0.153^{\mathrm{c}} \pm 0.03$ & $0.153^{\mathrm{c}} \pm 0.03$ & $0.153^{\mathrm{b}} \pm 0.08$ \\
20 day & $0.233^{\mathrm{c}} \pm 0.03$ & $0.206^{\mathrm{b}} \pm 0.03$ & $0.206^{\mathrm{b}} \pm 0.06$ & $0.200^{\mathrm{b}} \pm 0.05$ & $0.170^{\mathrm{b}} \pm 0.01$ \\
40 day & $0.360^{\mathrm{b}} \pm 0.05$ & $0.303^{\mathrm{a}} \pm 0.00$ & $0.353^{\mathrm{a}} \pm 0.02$ & $0.296^{\mathrm{a}} \pm 0.00$ & $0.266^{\mathrm{a}} \pm 0.01$ \\
\hline
\end{tabular}

C: control without antioxidants.

C1: Mayonnaise treated with 200 ppm BHA (positive control).

T1, T2, T3: Mayonnaise treated with 200, 400 and 600 ppm skin cantaloupe extracts, respectively.

* Means Values with different letters within the same column are statistically different $(\mathrm{p}<0.05)$.

Values are expressed as mean \pm SE.

Table 5. Effect of cantaloupe skin extract concentration on acid value AV $(m g \mathrm{KOH} / \mathrm{g}$ fat $)$ of Mayonnaise $(n=3)$. *

\begin{tabular}{lllll}
\hline \multirow{2}{*}{ Treatment } & days & & \\
\cline { 2 - 5 } & $\mathbf{0}$ & $\mathbf{2 0}$ & $\mathbf{4 0}$ & $\mathbf{6 0}$ \\
\hline $\mathrm{C}$ & $0.100^{\mathrm{a}} \pm 0.00$ & $0.233^{\mathrm{a}} \pm 0.03$ & $0.360^{\mathrm{a}} \pm 0.05$ & $0.523^{\mathrm{a}} \pm 0.01$ \\
$\mathrm{C} 1$ & $0.100^{\mathrm{a}} \pm 0.00$ & $0.190^{\mathrm{ab}} \pm 0.05$ & $0.206^{\mathrm{b}} \pm 0.03$ & $0.303^{\mathrm{c}} \pm 0.00$ \\
$\mathrm{~T} 1$ & $0.101^{\mathrm{a}} \pm 0.00$ & $0.153^{\mathrm{b}} \pm 0.03$ & $0.206^{\mathrm{b}} \pm 0.06$ & $0.353^{\mathrm{b}} \pm 0.02$ \\
$\mathrm{~T} 2$ & $0.100^{\mathrm{a}} \pm 0.00$ & $0.153^{\mathrm{b}} \pm 0.03$ & $0.200^{\mathrm{b}} \pm 0.05$ & $0.296^{\mathrm{c}} \pm 0.00$ \\
T3 & $0.103^{\mathrm{a}} \pm 0.01$ & $0.153^{\mathrm{b}} \pm 0.08$ & $0.170^{\mathrm{c}} \pm 0.01$ & $0.266^{\mathrm{c}} \pm 0.01$ \\
\hline
\end{tabular}

C: control without antioxidants.

C1: Mayonnaise treated with $200 \mathrm{ppm}$ BHA (positive control).

T1, T2, T3: Mayonnaise treated with 200, 400 and 600 ppm skin cantaloupe extracts, respectively.

*Means Values with different letters within the same column are statistically different $(\mathrm{p}<0.05)$.

Values are expressed as mean $\pm \mathrm{SE}$.

Thesis finding attributed to cantaloupe skin extract contains high levels of phenolic compounds; these compounds have antioxidative effects and possessed antihydrolytic effects during storage. The mechanism of antioxidant activity of these compounds consists in their capability of radical scavenging, metal chelating, and synergism with other antioxidants (Yemis et al., 2008). The finding results are agreement with Ismail et al., (2010) who reported that peanut skins ethanol $80 \%$ extracts $(200 \mathrm{ppm})$ showed the lowest increase in AV compared with other extracts and BHA at same ratio (200 ppm).

- peroxide values

Determination of peroxide value (PV) can give an idea about the early stages of oil oxidation. It is a measure the concentration of peroxides and hydroperoxides formed during the initial stages of lipid oxidation. Peroxide value is one of the most widely used tests for oxidative rancidity in oils and products contain high fats. For this, oxidation degree on mayonnaise samples was determined by measuring PV in the absence and presence on synthetic antioxidants and skin cantaloupe extract as source for natural antioxidants at $40^{\circ} \mathrm{C}$ temperature for 60 days. (Table 6) presents the peroxide values of mayonnaise blended with different portions of skin cantaloupe extract. The peroxide values for the fresh mayonnaise were very low which indicate the high quality of the oils used in this mayonnaise. The range of peroxide values for the fresh mayonnaise was $0.68-0.71$ meq. $02 / \mathrm{kg}$ oil. Also, the result of PV in the 20, 40, and 60 day show the control value was significantly higher than all sample treated as shown in table (6). No significant between samples treated with BHA and cantaloupe skin extract at level 400 and 600 ppm at every time $\mathrm{PV}$ was measured.

Table 6. Effect of cantaloupe skin extract concentration on peroxide value $P V($ meq.O2 $/ \mathrm{kg}$ fat) of Mayonnais $(n=3)$. *

\begin{tabular}{lllll}
\hline \multirow{2}{*}{ Treatment } & Days & & \\
\cline { 2 - 5 } & $\mathbf{0}$ & $\mathbf{2 0}$ & $\mathbf{4 0}$ & $\mathbf{6 0}$ \\
\hline $\mathrm{C}$ & $0.71^{\mathrm{a}} \pm 0.00$ & $2.74^{\mathrm{a}} \pm 0.08$ & $10.59^{\mathrm{a}} \pm 0.05$ & $13.73^{\mathrm{a}} \pm 0.29$ \\
$\mathrm{C} 1$ & $0.71^{\mathrm{a}} \pm 0.00$ & $1.70^{\mathrm{b}} \pm 0.00$ & $5.03^{\mathrm{c}} \pm 0.08$ & $6.60^{\mathrm{c}} \pm 0.05$ \\
$\mathrm{~T} 1$ & $0.70^{\mathrm{a}} \pm 0.05$ & $1.71^{\mathrm{b}} \pm 0.00$ & $5.60^{\mathrm{b}} \pm 0.09$ & $7.26^{\mathrm{b}} \pm 0.18$ \\
$\mathrm{~T} 2$ & $0.70^{\mathrm{a}} \pm 0.00$ & $1.68^{\mathrm{b}} \pm 0.01$ & $4.61^{\mathrm{c}} \pm 0.10$ & $6.56^{\mathrm{c}} \pm 0.07$ \\
T3 & $0.68^{\mathrm{a}} \pm 0.02$ & $1.76^{\mathrm{b}} \pm 0.14$ & $4.76^{\mathrm{c}} \pm 0.06$ & $6.53^{\mathrm{c}} \pm 0.12$ \\
\hline
\end{tabular}

C: control without antioxidants.

C1: Mayonnaise treated with 200 ppm BHA (positive control).

T1, T2, T3: Mayonnaise treated with 200, 400 and 600 ppm skin cantaloupe extracts, respectively.

* Means Values with different letters within the same column are statistically different $(\mathrm{p}<0.05)$.

Values are expressed as mean $\pm \mathrm{SE}$. 
From table (7), it is clear that control mayonnaise has crossed the threshold limit of PV according to Standards for edible fats and oils (10 meq. of peroxide/kg oil) after 40 days of storage. Also, control mayonnaise has reached the maximum PV (13.73 \pm 0.29 meq. of peroxide $/ \mathrm{kg}$ oil) after 60 days of storage. From table (7), it can be seen that there increases significantly in PV for all sample treated after storage than 0 day, However samples treated with BHA and cantaloupe skin extract at level 400 and $600 \mathrm{ppm}$ is still below the acceptable level at the end day of storage $(6.60 \pm 0.05,6.56 \pm 0.07$ and $6.53 \pm 0.12$ meq. of peroxide $/ \mathrm{kg}$ oil, respectively). The our results revealed that cantaloupe skin methanolic extracts under study, at a concentration of $400 \mathrm{ppm}$, could be used to retard mayonnaise auto-oxidation. These findings were expected due to the presence of high levels of natural antioxidants phenolic compound in cantaloupe skin extract, which act as potent antioxidants during storage. This finding is agreement with previous study Ismail et al., (2010) who concluded that ethanol extracts of peanut skins and pomegranate peels gave good antioxidant activity during accelerated oxidative incubation of ghee.

Table 7. Effect of different concentration from cantaloupe skin extract on the PV during storage mayonnaise. ( $n=3)$. *

\begin{tabular}{|c|c|c|c|c|c|}
\hline \multirow{2}{*}{ Storage } & \multicolumn{5}{|l|}{ Treatment } \\
\hline & C & C1 & T1 & T2 & T3 \\
\hline 0 day & $0.71^{\mathrm{d}} \pm 0.00$ & $0.71^{\mathrm{d}} \pm 0.00$ & $0.70^{\mathrm{d}} \pm 0.05$ & $0.70^{\mathrm{d}} \pm 0.00$ & $0.68^{\mathrm{d}} \pm 0.02$ \\
\hline 20 day & $2.74^{\mathrm{c}} \pm 0.08$ & $1.70^{c} \pm 0.00$ & $1.71^{\mathrm{c}} \pm 0.00$ & $1.68^{\mathrm{c}} \pm 0.01$ & $1.76^{\mathrm{c}} \pm 0.14$ \\
\hline 40 day & $10.59^{b} \pm 0.05$ & $5.03^{b} \pm 0.08$ & $5.60^{b} \pm 0.09$ & $4.61^{b} \pm 0.10$ & $4.76^{b} \pm 0.06$ \\
\hline 60 day & $13.73^{\mathrm{a}} \pm 0.29$ & $6.60^{\mathrm{a}} \pm 0.05$ & $7.26^{\mathrm{a}} \pm 0.18$ & $6.56^{\mathrm{a}} \pm 0.07$ & $6.53^{\mathrm{a}} \pm 0.12$ \\
\hline
\end{tabular}

C: control without antioxidants.

C1: Mayonnaise treated with 200 ppm BHA (positive control).

T1, T2, T3: Mayonnaise treated with 200, 400 and 600 ppm skin cantaloupe extracts, respectively.

*Means Values with different letters within the same column are statistically different $(\mathrm{p}<0.05)$.

Values are expressed as mean $\pm \mathrm{SE}$.

\subsection{Organoleptic Evaluation}

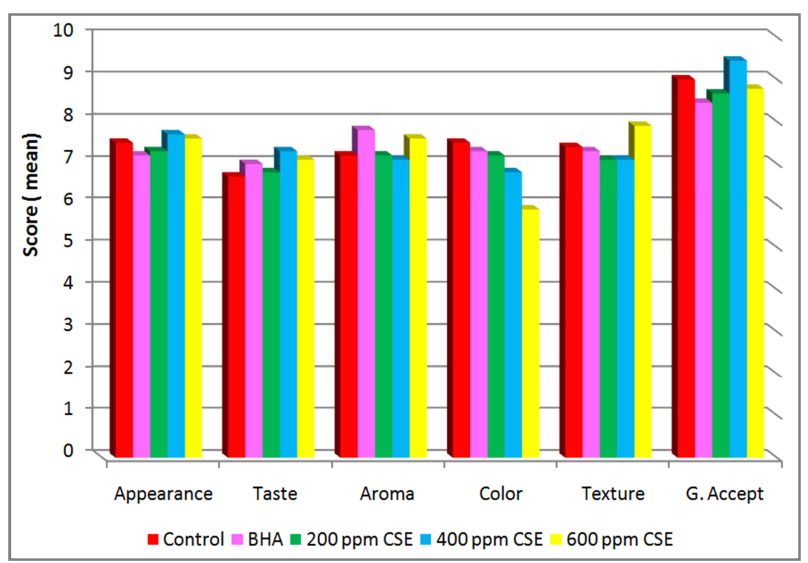

Fig. 4. Organoleptic characteristics of mayonnaise treated with different concentration of cantaloupe skin extract.

The results of score sheet analysis of color, aroma and general acceptability were shown in figure 4. Organoleptic evaluation of mayonnaise revealed that in a ten-point, generally all sensory results were Similar, it was in the range of 7- 9 indicating that these mayonnaise were highly acceptable. The best color of mayonnaise was observed in case of mayonnaise control but the difference was very weak and not significant compared of other samples. Mayonnaise treated with $400 \mathrm{ppm}$ of CSE had the best taste (7.3 \pm 0.33$)$ compared to control $6.7 \pm 0.85$. Mayonnaise with addition BHA had the worst one of appearance $7.2 \pm 0.81$ while mayonnaise treated with $400 \mathrm{ppm}$ of CSE had the best one $7.7 \pm 0.47$ but also the differences was not significant. The results suggested that no statistically significant differences at $(\mathrm{p}<0.05)$ were found between major characteristic tested.

Mayonnaise treated with cantaloupe skin extract at different portions had a good valuation of their features, and these results suggest that these Mayonnaise treated with CSE at level $400 \mathrm{ppm}$ were pretty acceptable for panelists.

\section{Conclusion}

High antioxidant activity were in parallel with their higher phenolic contents is observed in the skin extract of cantaloupe as compared to other tested extracts. Thus, these extracts can be considered as new sources of natural antioxidants for food and nutraceutical products. These extracts could be used as preservative ingredients in the food industries.

\section{Recommendation}

The recommendation that the extracts could be used as preservative ingredients in the food, cantaloupe skin extract at level $400 \mathrm{ppm}$ were found to be effective in retarding the oxidation of mayonnaise.

\section{References}

[1] $A O A C$, (2000): Official methods of analysis of the association of agricultural chemists, $17^{\text {th }}$ edition. Washington (US): Association of Official Analytical Chemists Inc (2000).

[2] Bala, B. K.; Morshed, M. A. and Rahman, M. F.(2009): Solar drying of mushroom using solar tunnel dryer., International solar food processing conference. 
[3] Balasundran, N., Sundram, K., Samman, S., (2006): Phenolic compounds in plants and agri-industrial by-products: antioxidant activity, occurrence and potential uses. Food Chem. 99, 191-203.

[4] Chang, S. T., Wu, J. H., Wang, S. Y., Kang, P. L., Yang, N. S., and Shyur, L. F. (2001): Antioxidant activity of extracts from Acacia confusa bark and heartwood. Journal of Agricultural \& Food Chemistry, 49(7), 3420-3424.

[5] Chenn, G., Xiong, Y. L., Wang, L., Gomez-Basauri, J., and Nicastro, F., (2008): Effect of preventox on the storage stability of raw and precooked pork patties. J. Muscle Foods $19,1-16$.

[6] Das N. P., and Pereira, T. A. (1990): Effects of flavonoids on thermal autooxidation of Palm oil: Structure activity relationship. J Am ChemSoc 1990; 67: 255-258.

[7] Dominick, S., and Derrick, R., (2001): Theory and problems of statistics and enconometrics, seconded. New York, USA, pp. 202-220.

[8] Ebrahimabadi, A. H., Diafari-Bidogoli, Z., Mazoochi, A., Kashi, F. J., and Batooli, H. (2010): Essential oil composition, antioxidant and antimicrobial activity of the leaves and flowers of Chaerophyllum macropodum Boiss. Food Control $21,1173-1178$

[9] Ghimire, B. K., Seong, E. S., Kim, E. H, Ghimerey, A. K., and $Y u, C$. Y., (2011): A comparative evaluation of the antioxidant activity of some medicinal plants popularly used in Nepal. J Med Plant Res 2011; 5(10): 1884-1891.

[10] Gulcin, I., Kufrevioglu, O. I., Oktay, M., Buyukokuroglu, M. E., (2004): Antioxidant, antimicrobial, antiulcer and analgesic activities of nettle (Urtica dioica L.). J. Ethnopharmacol. 90, 205-215.

[11] Heim, K. E., Taigliaferro, A. R., Bobilya, D. J., (2002): Flavonoid antioxidants: chemistry, metabolism and structureactivity relationships. J. Nutr. Biochem. 13, 572-584.

[12] Ismail, M., Hajar Iqbal Ismail, H. I., Chan, K. W., Mariod, A. A. (2010): Phenolic content and antioxidant activity of cantaloupe (cucumis melo) methanolic extracts, Food Chemistry 119 (2010) 643-647.

[13] Jang, H. A., Kim, Y. P., Kim, H. S., (2012): Effect of natural antioxidants on the oxidation of microencapsulated seed oil. Food Control 23, 528-534.

[14] Kessler., M, Ubeaud, G., Jung, L. (2003): Anti and pro oxidant activity of rutin and quercetin derivatives. J Pharm Pharmacol 2003; 55: 131-142.

[15] Jo, S. C., Nam, K. C., Min, B. R., Ahn, D. U., Cho, S. H., Park, $W$. P., and Lee, $S$. C., (2006): Antioxidant activity of Prunus mume extract in cooked chicken breast meat. Int. J. Food Sci. Technol. 41, 15-19.

[16] Kequan, Z., and Liangli, Y., (2004): Effects of extraction solvent on wheat bran antioxidant activity estimation. LWT Food Sci. Technol. 37, 717-721.

[17] Lanza, C., Pagiaini, E. and Tamseli, F. (1995): Sensory and chemical evaluation of frozen blood orange juice. Journal of Agric. Mediterranean., Volume 125, Pages 421-426.

[18] Mariod, A. A., Ali, R. T., Ahmed, Y. A., Abdel-Wahab, S. I., Abdul, A. B., (2010): Effect of the method of processing on quality and oxidative stability of anhydrous butter fat (samn). Afr. J. Biotechnol. 9, 1046-1051.
[19] Mariod, A. A., and Matthaus, B. (2008): Investigations on fatty acids, tocopherols, sterols, phenolic profiles and oxidative stability of Cucumis melo var. agrestis oil. Journal of Food Lipids, 15(1), 42-55.

[20] Meda, A., Lamien, C. E., Romito, M., Millogo, J. and Nacoulma, O. G. (2005): Determination of the total phenolic, flavonoid and praline contents in Burkina Fasan honey, as well as their radical scavenging activity. Food Chemistry, 91(3), 571-577.

[21] Mehta, B., 2006. Ragi (Coracana eleusine L.), a natural antioxidant for ghee (butter oil). Int. J. Food Sci. Technol. 41, 86-89.

[22] Miliauskas, G., Venskutonis, PR, Van Beek, T. A. (2004): Screening of radical scavenging activity of some medicinal and aromatic plant extracts. Food Chem; 85: 231-237.

[23] Moure, A., Jose, M., Demal, F., Manuel, D., Carlos, P., (2001): Natural antioxidants from residual source. Food Chemistry $72,145-171$.

[24] Pitchaon, M., Maitree, S., and Rungnaphar, P., (2007): Assessment of phenolic content and free radical-scavenging capacity of some Thai indigenous plants. Food Chem. 100, 1409-1418.

[25] Prakasha, J. G. K., Singh, R. P., Sakariah, K. K., (2001): Antioxidant activity of grape seed (Vitis vinifera L.) extracts on peroxidation models in vitro. Food Chem. 73, 285-290.

[26] Quettier-Deleu, C., Gressier, B., Vasseur, J., Dine, T., Brunet, C., Luyckx, M., et al. (2000): Phenolic compounds and antioxidant activities of buckwheat (Fagopyrum sculentum Moench) hulls and flour. Journal of Ethnopharmacology, 72, $35-42$.

[27] Randall, T. (2012): Perfect mayonnaise recipe: Recipes: Good Food Channel. Retrieved 26 December 2012.

[28] Riedel, H., Akumo, D. N., Saw, N. M. M. T., Smetanska, I., Neubauer, P., (2012): Investigation of phenolic acids in suspension cultures of Vitis vinifera stimulated with indanoylisoleucine, N-linolenoyl-Lglutamine, malonyl coenzyme A and insect saliva. Metabolites 2, 165-177.

[29] Ritschel, P. S., T. C. de Lima Lins, R. L. Tristan, G. S. C. Buso, A. Buso and M. E. Ferreira, (2004): Development of microsatellite markers from an enriched genomic library for genetic analysis of melon Cucumis melo L. Br. Med. Chem. Plant Biol., 14: 1-14.

[30] Rodriguez, J., Olea-Azar, C., Cavieres, C., Norambuena, E., Delgado-Castro, T., Soto-Delgado, J., et al. (2007): Antioxidant properties and free radical-scavenging reactivity of a family of hydroxynaphthalenones and dihydroxyanthracenones. Bioorganic \& Medicinal Chemistry, 15(22), 7058-7065.

[31] Saad, B., Yong, Y. S., Mohd, A. N., Noorhasani, H., Abdussalam, S. M. A., Muhammad, I. S., Saida, F. S., Khariuddin, M. T., Kamarudzaman, A. (2007): Determination of synthetic phenolic antioxidants in food items using reversed-phase HPLC. Food Chem. 105, 389-394.

[32] Soares, J. R, Dins, T. C. P., Cunha, A. P., Almeida, L. M. (1997): Antioxidant activity of some extracts of Thymus zygis. Free Radic Res 26: 469-478.

[33] Sroka, Z. and Cisowski, W. (2003): Hydrogen peroxide scavenging antioxidant and anti-radical activity of some phenolic acids. Food Chem Toxicol 41: 753-758. 
[34] Vouldoukis, I., Lacan, D., Kamate, C., Coste, P., Calenda, A., Mazier, D., et al. (2004). Antioxidant and anti-inflammatory properties of a Cucumis melo LC. extract rich in superoxide dismutase activity. Journal of Ethnopharmacology, 94(1), 6775 .

[35] Xiaowei, M., Hongxia, W., Liain, L., Quansheng, Y., Songbiao, W., Rulinzhan, S., Shanshan, X., Yigang, Z., (2011): Polyphenolic compounds and antioxidant properties in mango fruits. Sci. Hort. 129, 102-107.

[36] Yanishlieva-Maslarova, N. V. (2001): Inhibiting oxidation. In J. Pokorny, N. Yanishlieva, \& M. H. Gordon (Eds.), Antioxidants in food: Practical applications (pp. 22-70). Cambridge: Woodhead Publishing Limited.
[37] Yemis, O., Bakkalbasi, E., Artik, N., (2008): Antioxidantive activities of grape (Vitis vinifers) seed extracts obtained from different varieties grown in Turkey. Int. J. Food Sci. Technol. $43,154-159$.

[38] Yi, Z., Yu, Y., Liang, Y., and Zeng, B. (2008): In vitro antioxidant and antimicrobial activities of the extract of Pericarpium Citri Reticulatae of a new citrus cultivar and its main flavonoids. LWT - Food Science and Technology, 41, 597-603.

[39] Yu, J., Ahmedna, M., Goktepe, I., (2005): Effects of processing methods and extraction solvents on concentration and antioxidant activity of peanut skin phenolics. Food Chem. 90, 199-206. 